\title{
As famílias e as crianças acolhidas: histórias mal contadas
}

Families and children in institutional host: badly recorded accounts

Las familias y los niños acogidos: historias mal contadas

\author{
Maria Ignez Costa Moreira* \\ Paula Maria Bedran ${ }^{* *}$ \\ Soraia Dojas M. S. Carellos ${ }^{* * *}$ \\ Ana Paula Carvalho Pereira Passos ${ }^{* * *}$
}

\begin{abstract}
Resumo
Este artigo éfruto da pesquisa "O impacto das medidas protetivas previstas pelo Estatuto da Criança e do Adolescente nos sistemas familiares: 20092011" (Fapemig), 5 que objetivou compreender a trajetória de crianças e adolescentes e suas famílias na rede de proteção. Entre as conclusões da pesquisa, observamos precariedade dos registros sobre a história pessoal e familiar das crianças e dos adolescentes. Os dados são por vezes lacunares e genéricos, o que contribui para a desconsideração da singularidade de cada família, bem como para a invisibilidade das crianças e dos adolescentes. Do ponto de vista dos sujeitos, essas histórias mal contadas dificultam a elaboração e superação das vivências e das condições que geraram o acolhimento institucional. Já do ponto de vista da política pública, acarreta por vezes ações desconectadas, superpostas e até mesmo irrefletidas pelos equipamentos que compõem a rede de proteção.
\end{abstract}

Palavras-chave: Medida de acolhimento institucional. Criança. Adolescente. Família. Rede de proteção.

\begin{abstract}
This article is the result of the study, "The impact of protective measures provided for by the Statute of the Child and the Adolescent on Family Systems: 2009-2011" (Fapemig). The research aimed to understand the trajectory of children and adolescents and of their families in the network.
\end{abstract}

\footnotetext{
Professora do Programa de Pós-Graduação em Psicologia da Faculdade de Psicologia da PUC Minas. Doutora em Psicologia Social pela PUC SP.

* Professora da Faculdade de Psicologia da PUC Minas. Mestre em Psicologia pela UFMG.

*** Professora da Faculdade de Psicologia da PUC Minas. Mestre em Psicologia pela UFRJ.

**** Professora da Faculdade de Psicologia da PUC Minas. Mestre em Psicologia pela UFRJ.

***** O projeto de "O impacto das medidas protetivas previstas pelo Estatuto da Criança e do Adolescente nos sistemas familiares” foi aprovado pelo Comitê de Ética em Pesquisa da PUC Minas (CAAE - 0262.0.213.000-09).
} 
Among the conclusions of the study we observed the precariousness of records on the personal and family history of children and adolescents. The data is sometimes deficient and generics which contributes to the considering of the uniqueness of each family and produces social, invisibility of children and adolescents. From the point of view of the subjects these badly recorded accounts hinder the development and overcoming experiences of the conditions that generated the institutional host. From the point of view of public policy, these disconnected actions, overlapping and even thoughtlessness of the bodies that comprise the network of protection or safety net.

Keywords: Measure institutional host. Child. Adolescent. Family. Protection network.

\section{Resumen}

Este artículo es el resultado del estudio, "El impacto de las medidas de protección previstas en el Estatuto del Niño y del Adolescente en sistemas familiares: 2009-2011" (Fapemig) con miras a comprender la trayectoria de los niños, niñas y adolescentes y sus familias en la red de protección. Entre las conclusiones del estudio se observó la precariedad de registros sobre la historia personal y familiar de los niños, niñas y adolescentes. Los datos son a veces deficientes y genéricos, lo que contribuye a la no consideración de la singularidad de cada familia, así como a la invisibilidad de los niños, niñas y adolescentes. Desde el punto de vista de los sujetos, estas historias mal contadas, obstaculizan el desarrollo y la superación de las experiencias y de las condiciones que generan el acogimiento institucional. Y desde el punto de vista de las políticas públicas implica a veces acciones desconectadas, superpuestas e incluso sin reflexión por parte de los equipos que forman la red de protección.

Palabras clave: Medida de acogida institucional. Niño. Adolescente. Familia. Red de protección.

\section{Introdução}

s medidas protetivas anteriores ao acolhimento institucional de crianças e
adolescentes, previstas pelo Estatuto da Criança e do Adolescente - ECA
(Lei n. 8.069/1990) e dispostas aparentemente de modo gradual, têm a intenção de preservar os laços familiares de origem, bem como o direito à convivência familiar das crianças e dos adolescentes. Essas medidas protetivas anteriores são as de advertência e de apoio psicossocial aos pais e (ou) 
responsáveis, a inclusão em programas sociais, tais como o "bolsa família" ou de geração de renda, em grupos de apoio sociofamiliar, e o encaminhamento para tratamento de saúde, especialmente daqueles membros da família envolvidos no uso abusivo de drogas lícitas ou ilícitas.

Todas essas medidas anteriores ao acolhimento institucional exigem da família um maior grau de adesão, além de uma rede de serviços conectada e ágil, capaz de agir na potencialização dos recursos materiais e simbólicos da família em prol de sua reorganização e autonomia. Já as medidas sétima (acolhimento institucional), oitava (inclusão em família acolhedora) e nona (inclusão em família substituta) teriam um caráter mais tutelar e seriam tomadas pela instância judicial.

No entanto, nem sempre essas medidas têm alcançado os objetivos previstos, ou seja, os de fazer cessar as ações de violação de direitos e de violência e de promover a reorganização e a potencialização dos recursos da família. Em alguns casos, nem sequer chegam a ser praticadas. O que temos constatado ao longo dos anos de trabalho com as casas de acolhimento institucional é que a sétima medida protetiva tem se antecipado às demais, levando a uma precipitação na retirada da criança e do adolescente do seu sistema familiar.

Esse contexto nos instigou a pesquisar os impactos das medidas protetivas anteriores ao acolhimento institucional sobre os sistemas familiares. Buscamos reconstituir a trajetória de vinte famílias incluídas na rede de proteção social, cujas crianças e adolescentes receberam a medida de acolhimento institucional. Utilizamos como fonte de dados os registros desses casos arquivados nas casas de acolhimento institucional e, com base neles, dirigimo-nos ao Conselho Tutelar, identificado como o ponto inicial para a inclusão da família na rede protetiva.

\section{$O$ contexto da pesquisa}

$\mathrm{Na}$ pesquisa dos prontuários nos conselhos tutelares de Belo Horizonte, examinamos os registros referentes às 20 famílias que tiveram suas crianças e adolescentes em medida de acolhimento institucional nas casas de uma associação situada em Belo Horizonte. O conjunto dessas 20 famílias totalizou 53 crianças e adolescentes acolhidos.

Entre os casos examinados, 19 crianças e adolescentes acolhidos entre 2004 e 2010 permaneciam na instituição. Considerando que a medida de acolhimento institucional tem caráter excepcional e provisório, é bastante 
significativo o fato de que crianças e adolescentes permaneçam sob essa medida por um tempo muito superior aos dois anos previstos na última revisão do Estatuto da Criança e Adolescente (ECA).

Esse fato aponta para as dificuldades em se promover, durante o período de acolhimento institucional, a reorganização da família de origem para que esta possa receber novamente suas crianças e adolescentes. $\mathrm{E}$ ainda, nos casos em que tal reinserção é impossível, a dificuldade em encaminhar essas crianças e adolescentes à adoção por famílias substitutas.

A medida de acolhimento institucional, portanto, revela a complexidade das ações que visam à restauração e ao fortalecimento de vínculos familiares, essenciais para que o direito à convivência familiar, previsto pelo ECA, se realize. Essa constatação reforça a importância das medidas protetivas anteriores ao acolhimento institucional, no sentido de que elas possam evitar a ruptura inevitável que a retirada das crianças e dos adolescentes de suas casas, ainda que provisória, provoca.

Entre os casos examinados, cinco não apresentavam registro de medidas anteriores ao acolhimento, dando margem a uma dupla interpretação: as medidas não foram realizadas ou, se foram, não houve um registro oficial sobre elas.

Nos outros 15 prontuários nos quais existiam registros de medidas anteriores, as informações eram imprecisas. Não foram encontradas justificativas para as decisōes tomadas e muito menos a articulação entre essas decisões e a história particular da criança e de sua família.

O prontuário de Bernardo' ilustra a precariedade da aplicação da lei e dos registros das importantes decisões tomadas sobre o destino da criança. Bernardo foi acolhido em 2006, quando tinha seis anos de idade. O motivo da aplicação da medida foi a negligência e o abandono. A identificação de sua mãe consta dos registros, mas o seu pai é mencionado como não identificado. $\mathrm{O}$ encaminhamento foi feito pelo Juizado da Infância e da Juventude (JIJ). Não há registros de medidas protetivas tomadas antes do acolhimento institucional nem do tempo em que Bernardo permaneceu acolhido. Ele foi adotado por um casal de estrangeiros.

Histórias de alto nível de complexidade, como a de Bernardo, assim reduzidas, sugerem uma abordagem da situação pautada em princípios gerais que orientam as políticas públicas de proteção. Contudo as tomadas de decisão em relação à criança não são registradas nas suas particularidades, nem se registra a participação das crianças e de suas famílias sobre o seu destino após a inclusão do grupo familiar na rede protetiva.

\footnotetext{
Nome fictício.
} 
O cenário encontrado em Belo Horizonte é semelhante ao descrito por Orionte (2010), que, na sua pesquisa documental dos prontuários das crianças acolhidas na cidade de Goiânia-GO, encontrou em alguns várias informaçōes sobre a criança e a família e, em outros, faltava até mesmo a data de nascimento das crianças.

Algumas justificativas são apresentadas pelos componentes da rede de apoio para a ausência de registros, com o objetivo de minimizar a gravidade dessa situação, que acaba sendo tomada como natural. A justificativa mais recorrente é a falta de tempo dos operadores das medidas protetivas, dada à urgência de tomada de decisões diante das graves situações de violência e violação de direitos (a metáfora muito usada pelos operadores é de que estão sempre "apagando incêndios"). Outras vezes, encontra-se uma resistência aos registros, associados a uma exigência puramente burocrática dos órgãos gestores.

No entanto, a ausência de registro revela também a falta de consideração da importância da história singular nas decisões sobre o destino daquela criança, como se todas as histórias fossem iguais, se repetissem e, de tanto se repetir, ficassem naturalizadas, sem causar estranheza e problematizações necessárias.

A escassez de registro sobre as medidas de pré-acolhimento e pós-acolhimento institucional e sobre o processo que levou a uma adoção ou mesmo ao retorno para a família de origem reforça a tese sobre a invisibilidade das crianças e das famílias como sujeitos sociais ativos, revelando uma sujeição desses protagonistas à condição passiva de protegidos e tutelados pelas políticas públicas. Sem os registros, não se pode conhecer a posição das famílias, e, quando existentes, tais registros muitas vezes se limitam à descrição do que fizeram os agentes dos equipamentos de proteção, usualmente sem nenhuma menção às declarações das famílias.

Mesmo nos casos em que o registro é mais detalhado, chama a atenção a ausência das declarações das próprias famílias, bem como das crianças e dos adolescentes, que pudessem revelar o ponto de vista deles sobre as suas próprias condiçóes, as suas opiniōes sobre as orientações que recebem, as suas avaliações sobre os seus próprios limites e potencialidades, as suas recusas e resistências diante das açôes da rede de proteção.

Histórias mal contadas (repletas de lacunas) reforçam o anonimato dessas crianças subtraídas em sua história de vida e estigmatizadas com o sobrenome de "criança abrigada". Criança abrigada passa a ser uma categoria de identidade coletiva, que uniformiza no lugar de singularizar. É interessante observar que, mesmo após a mudança nos textos oficiais da nomenclatura "abrigo" para "acolhimento institucional", as crianças e os adolescentes continuam sendo chamados de "abrigados" e as casas de acolhimento institucional, de "abrigo".

A criança abrigada é, muitas vezes, criança sem passado e, embora se 
afirme, do ponto de vista legal, o direito à convivência familiar e comunitária, a criança excluída dessa convivência, uma vez institucionalizada, tem suas raízes abaladas, seus vínculos familiares e culturais fragilizados. As crianças, em sua particularidade, desaparecem nos registros de suas histórias.

A falta ou a precariedade dos registros revela, de certo modo, um hiato entre a intenção da lei e a prática cotidiana dos diversos equipamentos de proteção social. Numa leitura atenta do ECA, observam-se alguns aspectos que buscam resguardar a condição singular das crianças. Entre eles, a definição de que as crianças e os adolescentes são sujeitos de direitos e pessoas em condição particular de desenvolvimento. Tanto a noção de sujeito quanto a de pessoa remetem à singularidade.

Em consequência dessa definição, o ECA normaliza não só as condições legais para a retirada da criança e do adolescente de sua família de origem como também as normas de funcionamento das casas de acolhimento institucional. As normas técnicas para os serviços de acolhimento institucional (Brasil, 2009), elaboradas pelo Conselho Nacional dos Direitos da Criança e do Adolescente (Conanda), reiteram as proposições do ECA ao orientarem que as práticas de proteção considerem a situação de cada criança. Nesse sentido, as casas de acolhimento institucional devem receber, no máximo, 15 crianças ou adolescentes, em um ambiente doméstico, uma casa semelhante às outras casas do bairro onde a instituição está localizada, sem placas na porta. Durante o período em que a criança ou o adolescente estiverem acolhidos, a instituição deve dispensar a eles tratamento individualizado, cuidar para que tenham um espaço onde possam guardar os seus objetos, por exemplo. No entanto, na prática, a aplicação da lei atual revela os mesmos vícios da assistência pré-ECA, quando as crianças retiradas de suas famílias eram colocadas em instituições totais e despersonalizadas, quando os responsáveis por sua proteção e assistência não tinham qualquer compromisso com as particularidades de sua história.

Ao precário registro da trajetória anterior ao acolhimento institucional da família acrescenta-se o precário investimento do registro institucional das crianças acolhidas. Sem recuperar a história, não é possível recuperar a memória, elaborar as vivências negativas, para que elas possam ser superadas. Sem história, não há a possibilidade de futuro. A falta de registros do período do acolhimento institucional traz a impressão de que esse é um tempo e uma vivência a serem esquecidos por todos: pelas crianças e pelas famílias. Nesse sentido é exemplar a orientação recebida por um de nossos estagiários, de cortar automaticamente os encontros com a criança a partir do momento em que ela é destinada à adoção internacional, como se as crianças adotadas 
tivessem de apagar a sua história passada, para construir, a partir do zero, uma nova história.

\section{A leitura do contexto}

Nossa proposta é problematizar o contexto apresentado com o auxílio da concepção de sujeito de Vygotsky (2007), da noção de rede de Sluski (1997) e da epistemologia da complexidade de Morin (2008).

A tese central da teoria de Vygotsky (2007) é que a psique é uma construção histórico-social: elemento inovador da Psicologia, porque é uma definição que aponta para uma articulação, para a superação das dicotomias dentro/ fora e indivíduo/sociedade. A psique, para esse autor, deveria ser estudada em transformação, levando-se em conta os mecanismos capazes de acelerar ou bloquear seu desenvolvimento.

O sujeito de Vygotsky (2007) é compreendido como uma unidade múltipla que não se totaliza, posto que está em constante transformação de si mesmo e do seu contexto, e que se realiza "na relação eu/outro, sendo constituído e constituinte do processo sócio-histórico" (Molon, 2003, p. 116). Apoiadas na Psicologia sócio-histórica, buscamos nos pautar pela concepção de que crianças e adolescentes são sujeitos ativos, que se constituem em seus contextos e, por outro lado, transformam e constituem os próprios contextos familiares $\mathrm{e}$ institucionais.

Consideramos que as diversas experiências vividas pelas crianças e adolescentes diante das medidas protetivas são potencialmente transformadoras de suas histórias pessoais e familiares, e que as crianças e os adolescentes transformam os diversos contextos nos quais transitam em sua trajetória pela rede de proteção. Para que esse sujeito possa realizar a sua potencialidade para a ação, é necessário que tenha espaço para expressar e elaborar as suas experiências.

O outro conceito de Vygotsky (2007) que possibilita sustentar a importância da história das crianças, dos adolescentes e de suas famílias é o da memória. $\mathrm{Na}$ concepção de Vygotsky (2007), a memória significativa é aquela que é mediada por signos. E os signos são ferramentas que auxiliam nos processos psicológicos.

Segundo Oliveira, para Vygotsky,

Os sistemas de representação da realidade - e a linguagem é o sistema simbólico básico de todos os grupos humanos - são, portanto, socialmente dados. É o grupo cultural onde o indivíduo 
se desenvolve que lhe fornece formas de perceber e organizar o real, as quais vão constituir os instrumentos psicológicos que fazem a mediação entre o indivíduo e o mundo (Oliveira, 1983, p. 36).

A família é uma instituição vital para a organização social e psíquica do ser humano. É nela, pelos processos de socialização primária, que o bebê se torna humano. Nesse processo, a aprendizagem da linguagem é fundamental. A linguagem, frisamos, como um sistema simbólico. A história singular de cada criança e de cada família é produzida nas interações significativas vividas internamente na família entre seus membros e destes com as demais instituições sociais.

Vygotsky afirma que "nós nos tornamos nós mesmos através dos outros" (Vygotsky, 1999, p. 56). Os outros são investidos de significação afetiva. A história da criança e de sua família precisa ser traduzida em linguagem, em símbolos que possibilitem a apropriação, a significação e a transformação da própria experiência.

Vygotsky afirmará, segundo Sirgado, que a mediação do outro é simbólica e tem um sentido profundo, pois é considerada como a própria condição para o desenvolvimento do ser humano.

Portanto, o que é internalizado das relações sociais não são as relações materiais, mas a significação que elas têm para as pessoas. Significação que emerge na própria relação. Dizer que o que é internalizado é a significação dessas relações equivale a dizer que o que é internalizado é a significação que o outro da relação tem para o eu; o que, no movimento dialético da relação, dá ao eu as coordenadas para saber quem é ele, que posição social ocupa e o que se espera dele (Sirgado, 2000, p. 66).

As relações estabelecidas pelas famílias, pelas crianças e pelos adolescentes com todos aqueles que são agentes da proteção social têm a possibilidade de serem mediações potencializadoras, mas, para isso, as famílias precisam ser acolhidas como agentes de transformação e apoiadas em seus movimentos de mudança e compreendidas em seus próprios contextos. Isso significa considerar que as famílias são plurais, diversas em sua organização e em seus modos de convivência.

No entanto, se a mediação do outro é anuladora das particularidades da criança e da família, ela contribuirá para uma destituição ainda mais potente da família como um local simbólico de constituição daquela criança. 
Teríamos então, no lugar de outro de apoio, um outro de desqualificação da experiência dessas famílias.

Vygotsky (2007) também buscou articular os aspectos cognitivos aos emocionais. Dessa forma, podemos compreender que a omissão e o silêncio sobre a história singular das crianças, dos adolescentes e de suas famílias retiram deles elementos fundamentais para que possam compreender suas relações e suas posições subjetivas e sociais e para que possam agir, produzindo nova organização de suas experiências.

Sawaia (1999) afirma que a afetividade é parte fundamental da condição humana e mostra que, muitas vezes, as ações de proteção aos pobres ficam restritas ao apoio material. $\mathrm{O}$ argumento da autora nos ajuda a pensar que as urgências da proteção de crianças e adolescentes em situação de riscos graves impedem muitas vezes a consideração de que eles são também sujeitos de afeto e de desejo e não somente de necessidade: "Perguntar por sofrimento e por felicidade no estudo da exclusão é superar a concepção de que a preocupação do pobre é unicamente a sobrevivência e que não tem justificativa trabalhar a emoção quando se passa fome" (Sawaia, 1999, p. 98).

Descuidar da história singular das crianças, dos adolescentes e de suas famílias incluídos na rede de proteção é desconhecer seus afetos, seus modos próprios de significar e enfrentar o sofrimento cotidiano. A invisibilidade desses sujeitos gera a sua desumanização. Ainda segundo Sawaia, "uma das ideias-força desse momento histórico é a subjetividade e seus correlatos, a emoção e o sentido pessoal. Porém, ao mesmo tempo em que se valoriza o afeto e a sensibilidade individual, assiste-se à banalização do mal do outro, à insensibilidade ao sofrimento do outro" (Sawaia, 1999, p. 106).

Podemos também supor que, do ponto de vista dos operadores do sistema de proteção, a falta ou a precariedade dos registros pode significar uma estratégia de defesa para evitar seu próprio sofrimento, por meio de certo afastamento das histórias tão sofridas com as quais lidam. Afinal, para que seja feito o registro, é preciso uma escuta qualificada que possibilite a elaboração do relato oral em um relato escrito. A experiência do nosso trabalho tem nos mostrado o quanto é habitual que esses profissionais que lidam cotidianamente com situações extremamente complexas de sofrimento não contem com o anteparo da preparação teórico-metodológica e do apoio psicológico no exercício de suas funções.

Tomando como base essa concepção de sujeito, só podemos pensar a formação de uma rede de apoio à interação dos sujeitos, se não quisermos ver a metáfora da 
rede substituída pela metáfora da manta de proteção que invade e sufoca a história dos vários componentes de um contexto.

Para Esteves de Vasconcellos, citando Speck e Attneave, "A expressão 'rede social' teria sido cunhada por antropólogos britânicos para descrever estruturas sociais, de amplitude e grau de intimidade comparáveis às das famílias e dos clãs, mas que não se baseiam unicamente no grau de parentesco" (Speck \& Attneave apud Vasconcellos, 2010, p. 125).

Esteves de Vasconcellos, inspirada em Sluski, propóe: "Vemos a rede social porque somos especialistas em vê-la e não porque existe assim, como uma forma claramente delineada" (Vasconcellos, 2010, p. 128). A rede é composta, alerta Sluski, pelos significados das histórias de seus componentes, e sendo ao mesmo tempo também geradora e depositária dessas narrativas, o seu centro é "arbitrário, flutuante e circunstancial" (Sluskim 1997, p. 136).

Para Sluski, a rede social afeta a saúde física e emocional do indivíduo e das famílias, que, por sua vez, afeta a rede social.

Essa dupla ação permite delinear círculos virtuosos nos quais a presença de uma rede social substancial protege a saúde do indivíduo e a saúde do indivíduo mantém a rede social, assim como círculos viciosos nos quais a presença de uma doença crônica - ou uma deficiência ou uma dificuldade crônica de qualquer tipo - numa pessoa afeta negativamente a rede social dessa pessoa (frequentemente com maior intensidade a rede que ultrapassa a família nuclear), o que, por sua vez, aumentará a retração da rede, e assim por diante, em espiral de deterioração recíproca (Sluski, 1997, p. 67).

Podemos constatar que a proposta de uma rede de assistência à criança e ao adolescente incorre em equívocos frequentes de um funcionamento circular vicioso, o qual pode dar lugar a açôes e decisões desconectadas das necessidades da criança, do adolescente e da família, já que a fragmentação ainda impera na convivência no contexto de acolhimento.

A precariedade dos registros ou a ausência deles se associa à criação de círculos viciosos, pois contribuem para a cronicidade da situação da criança e da família na rede. Elas vivenciam sucessivos acolhimentos sem a atenção especial às causas da sua reincidência na rede de apoio e proteção.

A proposta de prática em rede que pretenda agir em consonância com a ideia de circulo virtuoso deve, necessariamente, atentar para os significados que reúnem os pontos dessa teia. Família e medidas protetivas do ECA constituem pontos de uma rede que deveria se afastar da noção de hierarquia 
e prevalência de um elemento sobre o outro, evitando práticas arbitrárias e invasivas da particularidade de cada sistema familiar e prevenindo também a repetição de sucessivos acolhimentos institucionais na vida da criança.

Morin nos auxilia na convicção da proposta do paradigma da complexidade, parceiro do conceito de rede, fornecendo uma ferramenta de análise que possibilita a disposição de uma abordagem ampla de vários fatores constituintes da medida de acolhimento institucional, realidade social que não pode ser apreendida por um paradigma determinista e redutor. "Estou cada vez mais convencido de que os conceitos dos quais nós nos servimos para conceber a nossa sociedade - toda sociedade - são mutilados e resultam em açôes inevitavelmente mutilantes" (Morin, 2008, p. 21-22).

Ao analisarmos as medidas protetivas anteriores ao acolhimento institucional e seus impactos nos sistemas familiares, faz-se necessário contemplar vários pontos simultaneamente coerentes com o pensar complexo: as medidas e as relaçôes entre si mesmas, as medidas e o acolhimento institucional, as crianças, os adolescentes e suas famílias e a rede envolvida (a casa, os diversos órgãos, como conselhos tutelares, sistema jurídico e outros).

Morin define a noção de complexidade:

Pode-se dizer que há complexidade onde quer que se produza um emaranhamento de açôes, de interações, de retroações. E esse emaranhamento é tal que nem um computador poderia captar todos os processos em curso. Mas há também outra complexidade que provém das existências de fenômenos aleatórios (que não podem ser determinados e que, empiricamente, agregam incerteza ao pensamento) (Morin, 1996, p. 274).

Pensar complexo é o desafio de exercitar a distinção entre as partes do contexto sem perder de vista as suas múltiplas conexões.

Os técnicos entrevistados durante a pesquisa são partes importantes desse contexto e também avaliam como precários os registros das crianças que se encontram sob essa medida. Alguns deles percebem a situação da seguinte maneira: "Pra você ter uma ideia, eu recebi uma criança do Conselho Tutelar que até o nome dele, na via de solicitação do abrigamento, veio errado. Não mandam relatório nenhum, por que estão encaminhando, quem é essa família..." (técnica da Casa 1). Tenho casos aqui de crianças em que a familia nem nunca foi advertida pelo Conselho Tutelar." (técnica da Casa 1).

Reconhecem a importância de se conhecer a história das crianças e dos adolescentes e a fragilidade de funcionamento da rede para viabilizar o 
conhecimento e o registro dos casos. Uma técnica entrevistada nos disse que se considera uma "detetive" rastreando a história das crianças, dos adolescentes e das famílias, buscando descobrir as conexões entre os diversos pontos da rede.

$\mathrm{O}$ acentuado apelo resolutivo que invade as práticas sociais dessa natureza pode acabar por produzir novos problemas, tais como o de acarretar uma lacuna de informaçôes que afeta o trabalho de outros profissionais em outros pontos da rede.

Para Morin (1996), quando dizemos "É complexo, é muito complexo", não estamos fornecendo uma explicação, mas sublinhando uma dificuldade para explicar os fenômenos em análise, pois essa é uma proposta de pensamento na qual estarão sempre presentes a dificuldade e a incerteza.

Ao recortarmos o ponto de análise deste trabalho (a precariedade dos registros e o acolhimento institucional das crianças sem necessariamente cumprirem-se as medidas anteriores), temos a convicção de que essa parte do contexto carrega em si mesma a marca do todo, já que nada está isolado; tudo está em uma relação solidária e, portanto, interfere nos desdobramentos do percurso da criança na rede.

Para a epistemologia da complexidade, a parte contém o todo, mas não é um simples reflexo do todo, guardando a sua particularidade e a sua potência de ação no contexto geral.

Ao longo do trabalho nas casas de acolhimento institucional, tem sido feito um exercício constante de "pensar pequeno", o que significa reconhecer a multiplicidade de elementos constitutivos do contexto de acolhimento e a dificuldade de abordá-los, em sua amplitude, de uma só vez. Significa assumirmos nossos limites em manejar situações das mais diversas ordens, evitando as decisões precipitadas em um fazer automático ou, por outro lado, a paralisação diante dos desafios que o contexto nos impõe. Estaremos, desse modo, agindo em sintonia com a complexidade, já que, se assumirmos a importância de uma atenção cuidadosa a um ponto da rede (o registro das histórias das crianças), potencializamos essas histórias e resguardamos as particularidades da criança para uma ação contextualizada em todos os pontos da rede.

\section{À guisa de conclusão}

Histórias mal contadas resultam em decisões precipitadas de desligamento ou retorno inadequado à família de origem; em encaminhamento para a adoção sem a escuta suficiente da criança, da família de origem e da família 
adotiva; e em longos períodos de acolhimento institucional, que pesam na construção da subjetividade dessas crianças. As histórias mal contadas são, na verdade, histórias mal escutadas e que revelam a pouca aposta na construção de espaços de conversação e na criação de novos significados para as crianças, os adolescentes e as famílias a partir da vivência do acolhimento institucional.

Entre as várias consequências da falta ou precariedade dos registros, destacamos a invisibilidade das crianças, dos adolescentes e de suas famílias, uma vez que a história delas se perde. Ao frequentar muitos pontos da rede, uma mesma família é levada a repetir a sua história para diversos interlocutores, uma repetição, por vezes, dolorosa.

A falta de registro também contribui para a desconexão da rede, uma vez que o desconhecimento da história das famílias e de sua trajetória na rede gera repetições de açôes que inserem todos os envolvidos em um círculo vicioso de difícil rompimento. Ainda do ponto de vista da política pública, há também um grande prejuízo, pois, sem os registros, não é possível planejar, avaliar e aprimorar as açôes.

Os registros lacunares da história das crianças, dos adolescentes e de suas famílias, se, de um lado, ocultam dificuldades e potencialidades das famílias, de outro revelam pontos de desconexão da rede. Desconhecer a história acarreta à rede de proteção ações descontínuas, superpostas e muitas vezes desnecessárias.

A pesquisa mostrou que a dificuldade com os registros não pode ser atribuída unicamente a uma resistência à burocracia ou ao ritmo frenético e imprevisível do trabalho necessário para que os diversos equipamentos da proteção social possam cumprir cada qual o seu papel. É preciso considerar também que as histórias revelam intenso sofrimento vivido pelas crianças, pelos adolescentes, pelas mães e pais, e que, por vezes, é quase indizível. Escutar as histórias acarreta perplexidade nos operadores da rede sofrimento. Assim, esses trabalhadores encontram dificuldades de registrar esses relatos ou de traduzi-los nos itens dos protocolos dos serviços.

Apesar de tudo, encontramos um esforço permanente em todos os segmentos da rede para fazê-la operar para o bem da criança, do adolescente e da família. São aqueles técnicos, conselheiros, educadores apaixonados pelo que fazem e defensores de uma relação única e diferenciada para cada família com seus filhos, e que lutam por uma prática em rede em prol dos interesses de cada um dos envolvidos na medida de acolhimento institucional, mas que também não conseguem um espaço legítimo de trocas e reflexões sobre as histórias vivenciadas por eles na experiência do acolhimento institucional. 
É possível, portanto, pressupor que as histórias das crianças e das famílias e as histórias dos operadores da rede não encontram registro expressivo na prática do acolhimento, o que pode resultar em uma prática desencarnada dessas histórias vividas pelos diversos protagonistas da rede.

Reconhecemos que, ao longo da trajetória de trabalho com o campo do acolhimento institucional, também fizemos parte da rede. Em alguns momentos conseguimos participar dela, contribuindo para transformar um círculo vicioso em virtuoso no sentido de construir intervenções que liberassem o potencial construtivo das famílias e dos seus filhos. No entanto, em outros momentos, não conseguimos efeitos positivos e libertadores de novas saídas para um destino mais justo para a criança e para o adolescente.

$\mathrm{Na}$ avaliação dos impactos das medidas protetivas anteriores à medida de acolhimento institucional, as lacunas encontradas nos registros foram evidentes e indicam a necessidade urgente da promoção de maior articulação dos diversos pontos da rede em prol do direito de crianças e adolescentes à convivência familiar e da promoção de meios materiais e simbólicos para que as famílias possam exercer o papel socialmente prescrito e compartilhado de proteção e defesa de suas crianças e adolescentes.

\section{Referências}

Brasil. Conselho Nacional dos Direitos da Criança e do Adolescente. (2009). Orientaçôes técnicas para o serviço de acolhimento institucional. Brasília: Conanda.

Brasil. Lei n. 8.069, de 13 de julho de 1990. (1990). Dispõe sobre o Estatuto da Criança e do Adolescente e dá outras providências. Brasília. Recuperado de http:// www.planalto.gov.br/ ccivil_03/Leis/L8069.htm.

Molon, S. I. (2003). Subjetividade e constituição do sujeito em Vygotsky. Petrópolis: Vozes.

Morin, E. (1996). Epistemologia da complexidade. In: D. F. Schnitman (Org.). Novos paradigmas, cultura e subjetividade. (pp. 274-286). Porto Alegre: Artes Médicas.

Morin, E. (2008). O método I: a natureza da natureza. Porto Alegre: Sulina,

Oliveira, M. K. (1983). Vygotsky. Aprendizado e desenvolvimento: um processo sóciohistórico. São Paulo: Scipione. 
Orionte, I. (2010). Crianças invisiveis: um estudo sobre o abandono e a_institucionalização na infância. Goiânia: Editora da PUC Goiás.

Sawaia, B. B. (1999). O sofrimento ético-político como categoria de análise da dialética exclusão/inclusão. In: B. B. Sawaia. As artimanhas da exclusão: análise psicossocial e ética da desigualdade social. (pp. 97-118). Petrópolis: Vozes.

Sirgado, A. P. (2000). O social e o cultural na obra de Vigotski. Educação e Sociedade, 71(21), 45-78.

Sluski, C. E. (1997). A rede social na prática sistêmica: alternativas terapêuticas. São Paulo: Casa do Psicólogo.

Vasconcellos, M. J. E. (2010). Redes Sociais: conceitos teóricos fundamentais para a prática. In: J. G, Aun, J. G., M. J. E. Vasconcellos \& S. V. Coelho. (Org.). Atendimento sistêmico de famílias e redes sociais. (Vol. 3, pp. 123-151). Belo Horizonte: Ophicina de Arte \& Prosa.

Vygotsky, L. S. (1999). Pensamento e linguagem. São Paulo: Martins Fontes.

Vygotsky, L. S. (2007). A formação social da mente. São Paulo: Martins Fontes. 